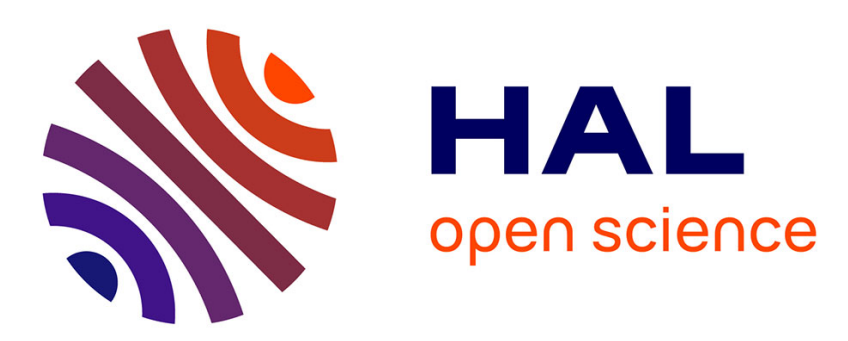

\title{
Shock-loading response of 6061-T6 aluminum-alumina metal-matrix composites
}

\author{
K. Vecchio, G. Gray
}

\section{To cite this version:}

K. Vecchio, G. Gray. Shock-loading response of 6061-T6 aluminum-alumina metal-matrix composites. Journal de Physique IV Proceedings, 1994, 04 (C8), pp.C8-231-C8-236. 10.1051/jp4:1994834 jpa00253389

\section{HAL Id: jpa-00253389 https://hal.science/jpa-00253389}

Submitted on 1 Jan 1994

HAL is a multi-disciplinary open access archive for the deposit and dissemination of scientific research documents, whether they are published or not. The documents may come from teaching and research institutions in France or abroad, or from public or private research centers.
L'archive ouverte pluridisciplinaire HAL, est destinée au dépôt et à la diffusion de documents scientifiques de niveau recherche, publiés ou non, émanant des établissements d'enseignement et de recherche français ou étrangers, des laboratoires publics ou privés. 


\title{
Shock-loading response of 6061-T6 aluminum-alumina metal-matrix composites
}

\author{
K.S. Vecchio and G.T. Gray III* \\ Dept. of Applied Mechanics and Engineering Sciences, University of CA, San Diego, LaJolla, CA 92093, \\ U.S.A. \\ * Materials Research and Processing Science, Los Alamos National Laboratory, Los Alamos, NM 87545, \\ U.S.A.
}

\begin{abstract}
Resumé
Les but de cette rechèrche est l'étude systimatique de l'ifluence de la pression maximum de choc et de la phase de renforcement sur la réponse méchanique (propriétés/structure) des composites $\mathrm{Al}$ alumine 6061-T6 sous chargement par choc. La réponse contrainte-déformation sous rechargement de l'aluminium monolothique montre qu'il n'ya pas d'augmentation d'écrouissage dynamique en comparison ou cas où le matériau n'à pas été initialement chargé par choc. La réponse contrainte-déformation des composites Al-alumine montre quer la résistance d'ecoulement du matériau initial. Les mesures des vitesses d'ondes pour les échantillons nonprédeformés par choc ne montrent aucune degradation en comparison aux échantillons nonprédeformés. La réponse contrainte-déformation sous rechargement du composite prédeformé, aprés resolution et veillissement $\mathrm{T} 6$, montre que le composite recouvre completement sa réponse à l'état initial.
\end{abstract}

\begin{abstract}
The purpose of this research is to systematically study the influence of peak-shock pressure and second-phase reinforcement on the structure/property response of shock-loaded 6061-T6 Alalumina composites. The reload stress-strain response of monolithic 6061-T6 Al showed no increased shock hardening compared to the unshocked material deformed to an equivalent strain. The reload stress-strain response of the shock-loaded 6061-T6 Al-alumina composites exhibits a lower reload yield strength than the flow stress of the starting composites. Wavespeed measurements of shock-prestrained specimens showed no degradation compared to un-shocked specimens, and reload stress-strain response of the shock-prestrained composites, after resolutionizing and T6 aging, showed that the composites recovered their full as-received stressstrain responses.
\end{abstract}

\section{INTRODUCTION}

Advanced composite materials are receiving increasing attention due to their tailorable properties. Composite materials allow other physical properties besides mechanical behavior such as: modulus, density, wave speeds, thermal conductivity, etc., to be custom designed to specific applications. The high-rate/impact response of advanced composite materials is relevant to a broad range of service environments such as the crash-worthiness of civilian/military vehicles, foreign-object-damage in aerospace applications, and light-weight armor. Increased utilization of these composite material under dynamic loading conditions requires an understanding of the relationship between high-rate/shock-wave response as a function of microstructure in order to guide future composite design and develop constitutive models to predict composite behavior. 
Several important aspects of MMCs in terms of their shock-loading response are: 1) MMCs are heterogeneous mixtures of often dramatically different constituents in terms of structural, physical, and mechanical properties, morphology, volume fractions, etc.; 2) MMCs exhibit elastic and plastic anisotropy, and 3) MMCs achieve some of their properties due to interfacial effects that influence plastic flow and fracture behavior. These three attributes can cause a broad range of effects on the structure/property relationships of composites subjected to shock loading. Increasing utilization of composite materials in future engineering designs will necessitate a fundamental understanding of how the deformation response of these complex multi-phase structures accommodate high-rate plastic deformation. In this paper the issues relevant to defect generation, storage, and their underlying physical basis for aluminum-based metal-matrix composites (MMCs) will be discussed.

The longitudinal wave speed and Hugoniot elastic limit (HEL) are, respectively: $6.4 \mathrm{~km} / \mathrm{s}$ and $0.6 \mathrm{GPa}$ for 6061-T6 aluminum, and $11.2 \mathrm{~km} / \mathrm{s}$ and $15.0 \mathrm{GPa}$ for alumina. Noting the large disparity in the HELs (a factor of $25 \mathrm{x}$ ) and a factor of $\sim 2$ difference in longitudinal wave speeds, the aluminum- $\mathrm{Al}_{2} \mathrm{O}_{3} \mathrm{MMCs}$ represent materials where: a) the shock wave will travel at different speeds in the two constituents, and b) at low shock pressures the $\mathrm{Al}_{2} \mathrm{O}_{3}$ will remain elastic while the matrix will readily deform plastically. Differences in shock velocity are known to influence the dispersive effects of the composite and thereby significantly change the loading and release wave profiles [1]. The dramatically different properties of the two constituents in MMCs, as well as the interfaces between these constituents, suggests that these materials will behave inherently different than their monolithic counterparts. Several important issues regarding the shock-loading response of metal-matrix composites must be addressed:

a) How do MMCs differ from pure metals in terms of their ability to store defects under shock-wave loading?

b) What microstructural changes occur in MMCs subjected to shock-wave deformation, and how are they manifested in their post-shock mechanical response?

\section{EXPERIMENTAL TECHNIQUES}

Monolithic 6061-T6 aluminum alloy and two 6061-T6 Al-alumina composites containing 10 vol.\% alumina particulate with either: nearly spherical (designated as MMC-C) or angular (designated MMC-D) morphologies, were selected for this study. Samples were shock-loaded to $5 \mathrm{GPa}$ using an $80 \mathrm{~mm}$ singlestage launcher [2], or $27 \mathrm{GPa}$ using explosives [3]; see indicated references for detailed shock loading procedures. In the case of the $27 \mathrm{GPa}$ shock recovery test the shock assembly contained the monolithic 6061-T6 aluminum as well as both MMC's to guarantee similar shock-prestraining conditions. Compression samples were machined from both the starting materials and the shock-recovered samples, and reloaded at a strain rate of $10^{-3} / \mathrm{s}$. Ultrasonic wavespeed measurements, both longitudinal and shearwave, were made on each material prior to and following the shock-recovery experiments. These measurements were made at a frequency which we have found to be well suited for detecting cracked particles in these MMCs. The major errors in these wave-speed measurements arise from inaccuracies is specimen thickness measurements; however these errors result in less than $1 \%$ change in the resultant wave-speed measurements.

\section{RESULTS AND DISCUSSION}

Figure 1 shows the initial microstructures of the two metal-matrix composites, and the monolithic 6061T6. The microstructures following the shock-loading experiments, as resolved by light optical examination, did not reveal any observable changes, such as: particle cracking or interface decohesion in the composites, or any non-uniform plastic deformation such as shear-banding, in either the monolithic material or the composites.

The stress-strain responses of the as-received and shock-loaded 6061-T6 aluminum and the two MMC's are given in Figures 2-4. It is interesting to examine the shock response of the monolithic 6061-T6 aluminum before investigating the composites. In Figure 2 the as-received 6061-T6 stress-strain data is plotted along with the reload stress-strain data for the shock-loaded 6061-T6 alloy. The reload curves for the shock prestrained materials in Figures 2-4 have been offset with respect to the as-received responses by the transient strain generated by the shock, defined as $4 / 3 \ln \left(V / V_{O}\right)$, where $V$ and $V_{O}$ are the final and initial volumes, respectively, of monolithic $6061 \mathrm{Al}$ alloy during the given shock cycle. The volumes utilized in this calculation assume the equation-of-state (EOS) response of monolithic 6061 for each case since the EOS's of the metal-matrix composites are unknown. This is thought to be a reasonable 
approximation given the low volume fraction $(\sim 10 \%)$ of alumina in the composites, and the similarity in longitudinal wave-speeds of the monolithic 6061-T6 and the two MMCs, which differ by only a few \%, as shown in Figure 6. Table 1 summarizes the flow stress data for each material tested; these data were taken as the reload yield strength of the shock-loaded samples and the flow stress at a strain equivalent to the transient shock strain for the as-received materials (taken as 0.28 for the $27 \mathrm{GPa}$ pressure and 0.075 for the $5 \mathrm{GPa}$ pressure).

The response of pure copper subjected to a $10 \mathrm{GPa}$ shock is also shown in Figure 2 for comparison. The reload stress-strain curve for the shock-loaded 6061-T6 Al shows no significant enhanced shock hardening compared to the quasi-statically deformed sample for an equivalent strain; whereas pure $\mathrm{Cu}$ shows a significant increase in strength resulting from the shock relative to the quasi-statically deformed sample $[2,4]$. This behavior is consistent with a previous study of reload shock response of 6061-T6 Al shock prestrained to either 7 or $13 \mathrm{GPa}$ [5]. These results indicate that shock-loading monolithic 6061 aluminum does not inherently alter the mechanical response compared to quasi-statically deformed material. This suggests that similar defect generation and storage mechanisms are operative for both processes.
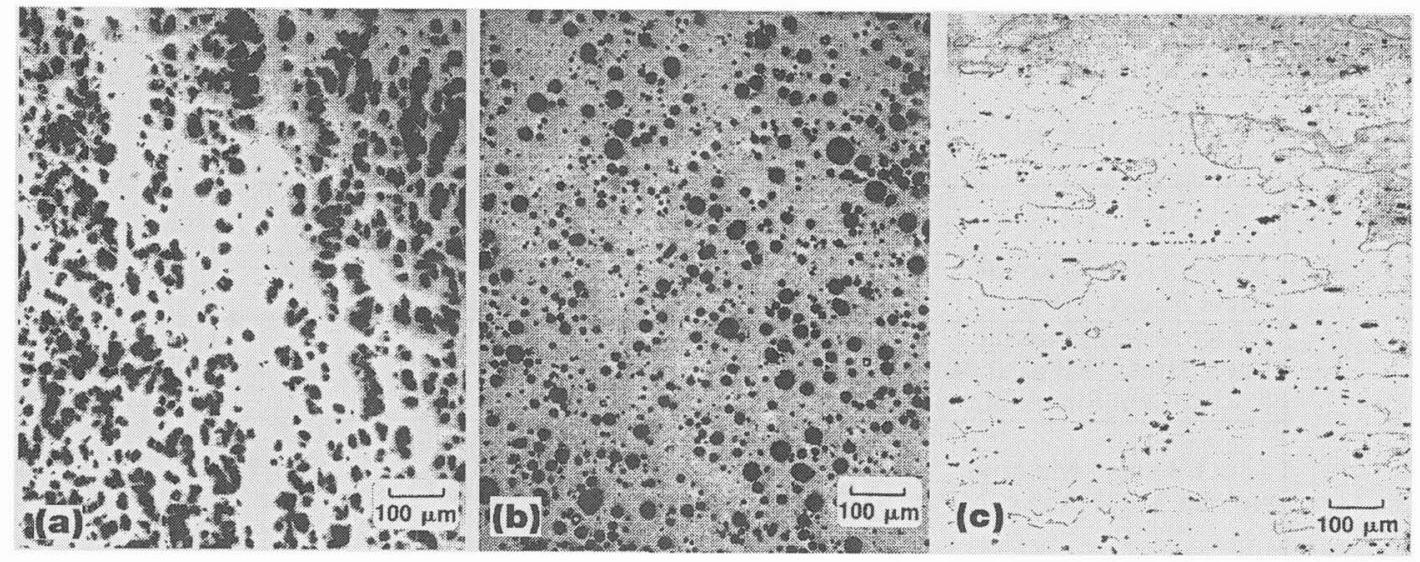

Figure 1 Optical micrographs of (a) 6061-T6 MMC-D, (b) 6061-T6 MMC-C, and (c) monolithic 6061-T6 aluminum.

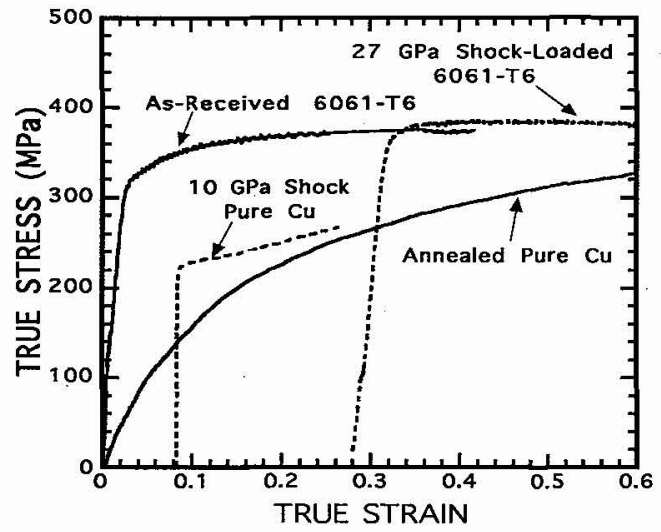

Figure 2 Stress-Strain response of 6061-Al T6 and pure $\mathrm{Cu}$ between as-received and shock-loaded conditions. Reload strain rate of $0.001 / \mathrm{s}$.

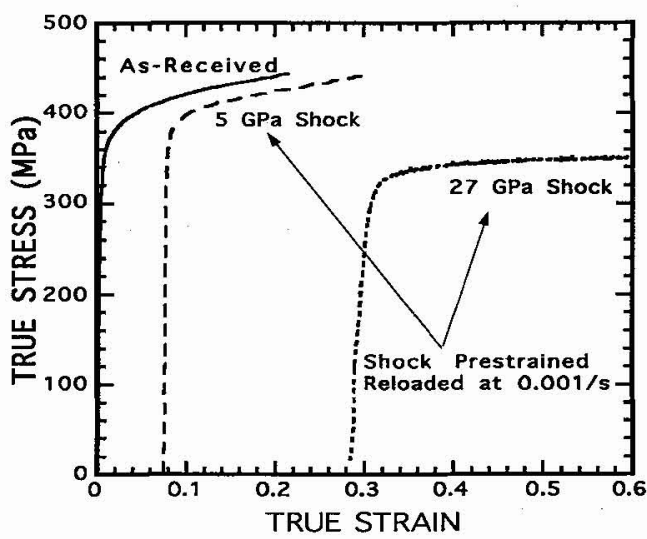

Figure 3 Stress-Strain response of $\mathrm{MMC}-\mathrm{C}$ as a function of peak shock pressure. Note the significant decrease in reload yield stress with increasing shock pressure. 
Figure 3 shows the stress-strain response for the MMC-C material subjected to $5 \mathrm{GPa}$ and $27 \mathrm{GPa}$ shocks, along with the initial as-received stress-strain data. The reload stress-strain curves for both shock prestrained samples exhibit lower flow stresses compared to the as-received material behavior, with the degree of strength loss increasing with increasing shock pressures from 5 to $27 \mathrm{GPa}$. Furthermore, the work hardening rate also degrades with increasing shock pressure. Figure 4 shows a comparison of the stress-strain responses of both of the metal-matrix composites (MMC-C and MMC-D) in the as-received and shock-loaded conditions. Both MMCs show similar decreases in flow stresses following the shock compared to the as-received conditions. In fact, the yield strength of the shock-prestrained composites, subjected to a $27 \mathrm{GPa}$ shock pressure, is lower than the yield strengths of the as-received materials without the shift in strain associated with the transient strain introduced by the shock. These observations suggest a major change in defect generation and storage mechanisms in the MMC's compared to the unreinforced 6061-T6 aluminum since all three were subjected to similar shock-prestraining conditions.

To examine the load transfer capability between the matrix and alumina operative in the composites following shock prestraining specimens of the shock-recovered materials were re-solutionized and peakaged to T6 condition and subsequently reloaded quasi-statically to measure the stress-strain response. If significant interface decohesion and/or particle cracking were present, the stress-strain behavior of the reheat-treated MMC's should exhibit reduced yield strengths and work-hardening rates compared to the as-received MMC's. As shown in Figure 5 the reheat-treated MMC's exhibited nearly identical stressstrain responses as the as-received MMC's.

Table 1. Summary of Flow Stresses for As-Received and Shock-Loaded Materials

\begin{tabular}{|l|c|c|c|}
\hline & $\begin{array}{c}\text { Monolithic } \\
6061-\mathrm{T} 6\end{array}$ & MMC-C & MMC-D \\
\hline $\begin{array}{l}\text { As-Received Material } \\
\text { Yield Stress (MPa) }\end{array}$ & 315 & 380 & 335 \\
\hline $\begin{array}{l}\text { As-Received Material } \\
\text { Flow Stress (MPa) at Strain Equal } \\
\text { to Transient Shock Strain }\end{array}$ & 370 & 420 & 410 \\
\hline $\begin{array}{l}\text { Shock-loaded Material } \\
\text { Reload Yield Stress (MPa) }\end{array}$ & $\begin{array}{c}\text { @ 27 GPa } \\
\text { Pressure }\end{array}$ & $\begin{array}{c}\text { @ 5 GPa } \\
\text { Pressure } \\
\text { 335 } \\
\text { @ }\end{array}$ & $\begin{array}{c}\text { @ 27 GPa } \\
\text { Pressure } \\
\text { Pressure }\end{array}$ \\
\hline
\end{tabular}

Additionally, to further investigate whether the decreased flow stresses of the reload curves for the shock prestrained samples was attributable to particle cracking and/or interface decohesion resulting from the shock, the longitudinal and shear wave-speeds of the pre- and post-shocked materials were measured. Figure 6 shows the results of these measurements, which indicate that the wave-speeds were essentially unchanged for both MMC's and the monolithic 6061-T6 Al before and after shock prestraining. The errors associated with the wave-speed measurements were determined to be less than $1 \%$ relative. This suggests that the $\sim 100 \mathrm{MPa}$ decrease in flow stresses and less protracted elastic-plastic transition of the two MMCs cannot be readily attributed to reduced load transfer capacity between the particles and matrix. This result coupled with the results shown in Figure 5 show that changes in the 6061-T6 Al matrix, rather than direct reinforcement strengthening effects, are controlling the post-shock mechanical response of the MMC's in this study. Other, yet unresolved effects must control the manner by which composites generate and store defects, as well as the stability of the shock-generated substructure to subsequent deformation.

In the shock process, contrary to a conventional uniaxial stress test, deformation encompasses a stress and strain path reversal during the compressive loading in the shock rise followed by the release [2]. The lower reload yield stress in shock-loaded hard-second-phase composites (i.e., MMC's) is consistent with a Bauschinger contribution [6]. A Bauschinger effect in the reloaded shock samples would be manifested in lower yield behavior after the strain-path reversal inherent in the shock and caused by the back stresses built up during the shock release. This is indeed the case in the current MMC's suggesting this may be contributory to the observed reload responses of the MMC's. However, the high-rate/shock response of composites must also consider additional influences of composite behavior on defect processes. 


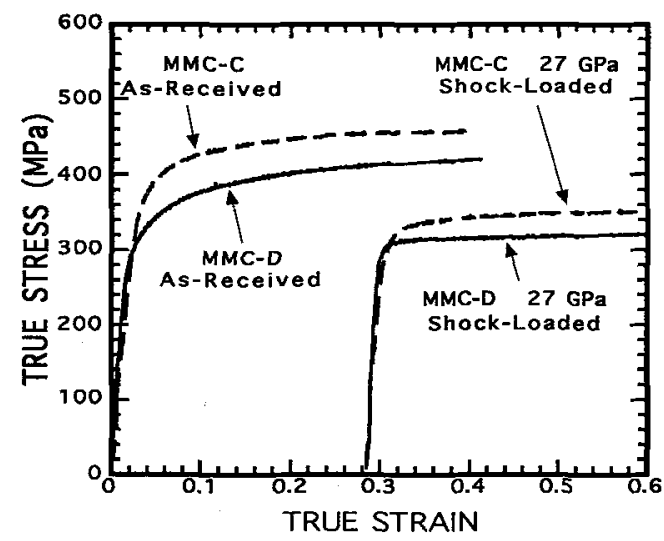

Figure 4 Stress-Strain response comparison of MMC-C and MMC-D between asreceived and shock-prestrained to 27 $\mathrm{GPa}$

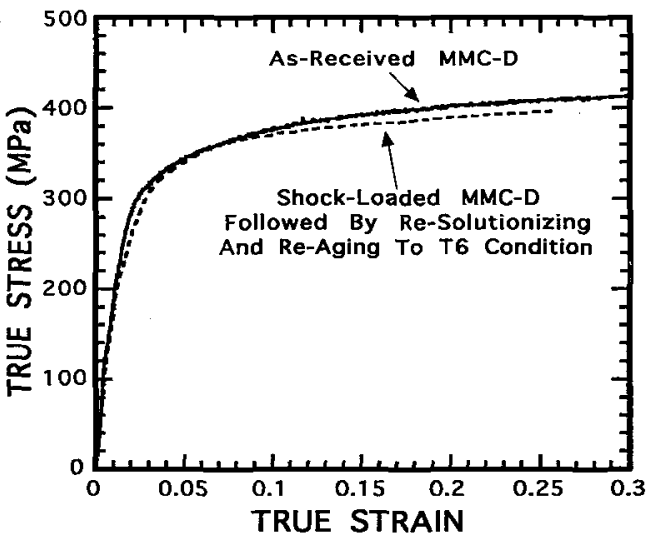

Figure 5 Stress-Strain response comparison of asreceived MMC-D T6 condition with post-shock reheat-treated sample showing recovered reload response indicating no load-transfer loss between particles and matrix.

Residual stresses are formed in most composites during processing due to the thermal expansion mismatches between constituents. During cooling dislocations are generated in the matrix in response to these stresses accounting for a major percentage of the increased yield strength of the composite. Whilethe role of these unrelieved stresses and dislocation networks on subsequent wave propagation and defect generation/storage mechanisms during shock loading is poorly understood, several plausible effects can occur. The reduction in the reload yield strength and work-hardening rates of the shock prestrained MMC's could be rationalized based upon: 1) alterations in the matrix microstructure due to the shock, 2) pronounced annihilation of the dislocations generated due to the reinforcements, at the particle/matrix interfaces, which would drastically reduce the yield strength or 3) instabilities in the substructure generated during the shock which upon reloading undergo localized reorganization resulting in a net lower yield stress and inability to sustain increased work-hardening. These alterations in the defect storage processes in the matrix may act independently or in concert with a Bauschinger effect contribution in MMC's as mentioned above. While all these possibilities are plausible, the first explanation, 'changes in the matrix microstructure' appears unlikely due to the fact the as-received 6061 aluminum, shocked simultaneously in the same fixture, does not exhibit a reduced reload yield strength. As such, the alternative explanations that shock prestraining of the MMC's has resulted in significant changes in the matrix substructure remain. Electron microscopy studies are necessary to characterize the differences in the substructure evolution between the as-received and shock-prestrained MMC's; these studies are ongoing.

\section{SUMMARY AND CONCLUSIONS}

The influence of shock pressure and microstructure on the structure/property response of 6061-T6 AI metal-matrix composites was investigated, using a monolithic 6061-T6 aluminum alloy as a baseline for comparison. The following conclusions can be drawn from the results: 1) the reload yield behavior of shock prestrained monolithic 6061 alloy exhibits no enhanced shock hardening compared to specimens deformed quasi-statically to an equivalent strain level; the absence of shock-enhanced hardening in this alloy is in stark contrast to pure FCC metals such as $\mathrm{Cu}$ and $\mathrm{Ni}$ which show significant shock hardening; 2) the reload yield behaviors of both metal-matrix composites shock prestrained to $5 \mathrm{GPa}$ or $27 \mathrm{GPa}$ exhibit lower reload yield stresses than their flow stresses achieved by quasi-static deformation to equivalent strains consistent with a 'Bauschinger' contribution to defect storage in these ceramicparticulate reinforced metal-matrix composites. The large (approx. $100 \mathrm{MPa}$ ) decrease in reload yield strength resulting from the $27 \mathrm{GPa}$ shock prestraining could not be attributed to contributions from particle cracking and/or interface decohesion. Extensive transmission electron microscopy is underway 
to elucidate the differences in substructure evolution between shock wave deformation and quasi-static deformation in MMC's.

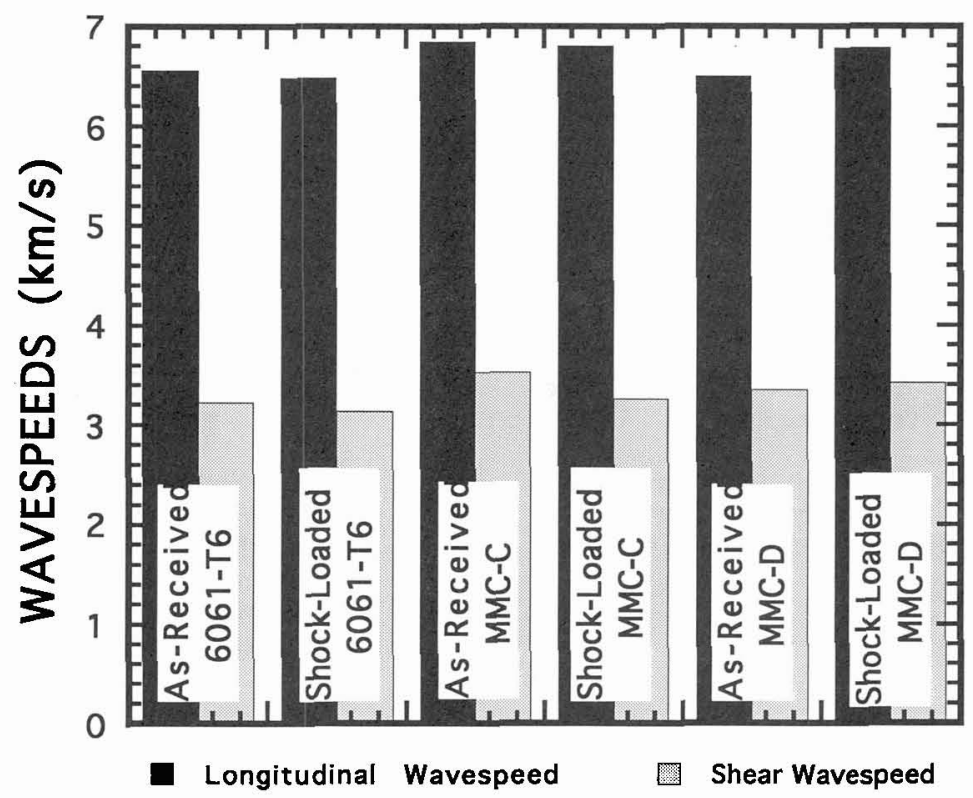

Figure 6 Longitudinal and shear wave-speeds measured before and after shock-prestraining on each of the three materials examined. Little or no change in wave-speeds is evident.

\section{ACKNOWLEDGMENTS}

KSV acknowledges the support of the Army Research Office through a URI grant \# ARO-DAAL-0392-G-0108 and the National Science Foundation grant \# DMR-9110930 for this research. GTG acknowledges the support of the United States Department of Energy. The materials (monolithic 6061 and MMC-D) were provided by DURALCAN, USA, San Diego, CA, and the material (MMC-C) was provided by Comalco Corp., Australia.

\section{REFERENCES}

[1] Bakrer, L.M., J. Comp. Matls., 5 (1971) 140-162.

[2] G.T. Gray III: in High Pressure Shock Compression of Solids, Edited by J.R. Asay and M. Shahinpoor, Springer-Verlag, New York (1993) pp. 187-215. [Book Chapter] "Influence of Shock-Wave Deformation on the Structure / Property Behavior of Materials".

[3] Meyers, M.A., Meyer, L.W., Vecchio, K.S., and Andrade, U., "High Strain, High Strain-Rate Deformation of Copper", (Journel de Physique, Colloque C3, suppl. au Journal de Physique III, Oct. 1991) 11-17.

[4] Vecchio, K.S. and Gray III, G.T., "Effects of Shock Loading on Solid-Solution Strengthened Superalloys", APS Topical Conference on Condensed Matter-1993 (North-Holland Press, N.Y., 1994) in press.

[5] Gray III, G. T. and P. S. Follansbee, Shock Waves in Condensed Matter 1987, S.C. Schmidt and N.C. Holmes, eds., North-Holland Press, pp. 339-342, 1988. "Influence of Peak Pressure on the Substructure Evolution and Mechanical Properties of Shock-Loaded 6061-T6 Aluminum".

[6] Hong, S.I., Gray III, G.T., and Lewandowski, J.J., Scripta Metall. 27 (1992) 431-436. 